\title{
The drug likeness analysis of anti-inflammatory clerodane diterpenoids
}

\author{
Zheling Feng, Jun Cao, Qingwen Zhang and Ligen Lin* ${ }^{*}$
}

\begin{abstract}
Inflammation is an active defense response of the body against external stimuli. Long term low-grade inflammation has been considered as a deteriorated factor for aging, cancer, neurodegeneration and metabolic disorders. The clinically used glucocorticoids and non-steroidal anti-inflammatory drugs are not suitable for chronic inflammation. Therefore, it's urgent to discover and develop new effective and safe drugs to attenuate inflammation. Clerodane diterpenoids, a class of bicyclic diterpenoids, are widely distributed in plants of the Labiatae, Euphorbiaceae and Verbenaceae families, as well as fungi, bacteria, and marine sponges. Dozens of anti-inflammatory clerodane diterpenoids have been identified on different assays, both in vitro and in vivo. In the current review, the up-to-date research progresses of anti-inflammatory clerodane diterpenoids were summarized, and their druglikeness was analyzed, which provided the possibility for further development of anti-inflammatory drugs.
\end{abstract}

Keywords: Clerodane diterpenoids, Anti-inflammation, Drug-likeness, SwissADME

\section{Background}

Inflammatory diseases include a vast array of disorders and defense reaction of organisms against external stimulations that are characterized by inflammation symptoms, such as allergy, autoimmune diseases, asthma, glomerulonephritis, hepatitis, inflammatory bowel disease (IBD), reperfusion injury and transplant rejection [1-3]. Long term low-grade inflammation has been considered to play a deteriorated role in many diseases, such as aging, cancer, metabolic disorders, and neurodegeneration [4-7]. The occurrence of chronic diseases has triggered prolonged inflammation that induces the expression of robust pro-inflammatory mediators and cytokines [8, 9], which lead to the pathogenesis of inflammation-associated chronic diseases. Tumor necrosis factor (TNF)- $\alpha$ is one of the most potent pro-inflammatory cytokines and signals [10, 11]. Through binding to its receptors, TNFR1 and TNFR2, TNF- $\alpha$ plays critical roles in

*Correspondence: ligenl@um.edu.mo

State Key Laboratory of Quality Research in Chinese Medicine, Institute of Chinese Medical Sciences, University of Macau, Avenida da Universidade, Taipa, Macau 999078, People's Republic of China apoptosis, cell proliferation and immune responses [11, 12]. Interleukin-1 $\beta$ (IL-1 $\beta$ ) is one of the inflammatory markers belonging to the IL-1 family of cytokines [13, 14]. IL-6 and IL-12 display a pro-inflammatory action via stimulating IL-1 secretion [15]. IL-10, as the most important anti-inflammatory cytokine, represses pro-inflammatory responses and limits inflammation-induced tissue disruptions [16, 17]. Prostaglandin E2 (PGE2) is derived from arachidonic acid produced by cyclooxygenase (COX)-1 and/or COX-2 [18], which is a principal mediator of inflammation in diseases such as rheumatoid arthritis and osteoarthritis [19]. Nitric oxide (NO) is free radical acting as a cellular signaling molecule in inflammation process [20, 21]. NO is synthesized from I-arginine through the action of nitric oxide synthase (NOS) family [22], which has been associated with the pathogenesis and progression of inflammatory-related diseases [20, 23]. Macrophages exit throughout the body, which play important roles in tissue development, inflammation and anti-pathogenic defense [24-26]. A variety of biologically active molecules related to the beneficial and harmful consequences of inflammation are produced by macrophages. Therefore, therapeutic intervention for

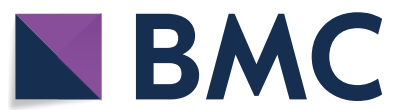

(c) The Author(s) 2020. This article is licensed under a Creative Commons Attribution 4.0 International License, which permits use, sharing, adaptation, distribution and reproduction in any medium or format, as long as you give appropriate credit to the original author(s) and the source, provide a link to the Creative Commons licence, and indicate if changes were made. The images or other third party material in this article are included in the article's Creative Commons licence, unless indicated otherwise in a credit line to the material. If material is not included in the article's Creative Commons licence and your intended use is not permitted by statutory regulation or exceeds the permitted use, you will need to obtain permission directly from the copyright holder. To view a copy of this licence, visit http://creativeco mmons.org/licenses/by/4.0/. The Creative Commons Public Domain Dedication waiver (http://creativecommons.org/publicdomain/ zero/1.0/) applies to the data made available in this article, unless otherwise stated in a credit line to the data. 
macrophages and their related products has attracted widespread attention in the treatment of inflammatory diseases. [24, 27].

Currently, the clinically used inflammation-treating drugs include non-steroidal anti-inflammatory drugs (NSAID) and glucocorticoids (SAID). Both classes of anti-inflammatory drugs could induce unpleasant side effects, and not suitable for chronic use [28-30]. Thus, it's urgent to discover and develop new effective and safe drugs to alleviate inflammation. Tons of scientific evidence has indicated that natural medicines represent a big treasure to develop potential therapeutic agents for inflammation-related diseases [31, 32]. The clerodane diterpenoids are a large class of naturally occurring bicyclic diterpenoids (Fig. 1), found in lots of plant species, especially the families of Labiatae, Euphorbiaceae and Verbenaceae [33]. More and more research interests have been attracted in recent years for their wide and potent biological activities [34]. Salvinorin A, a clerodane diterpenoid isolated from Salvia divinorum, was found as an agonist of the $\mathrm{k}$-opioid receptor. It is the first opioid receptor agonist without nitrogen and non-alkaloid hallucinogen. Many clinical trials results support the physiological effects of salvinorin A is mediated through K-opioid receptor-serotonin-2A pathway [35-40]. A lot of studies have disclosed the potential anti-inflammatory activity of clerodane diterpenoids. Herein, an up-to-date and comprehensive review of clerodane diterpenoids with anti-inflammatory property was provided, and their drug-likeness was analyzed through SwissADME, which enable further development of clerodane diterpenoids for the treatment of inflammation related diseases.

\section{Clerodane diterpenoids with anti-inflammatory property}

Data was collected from Web of Science, Google Scholar, Scopus, and Pubmed via using the keywords clerodane diterpenoid and inflammation, and a total of 65 clerodane diterpenoids were found with
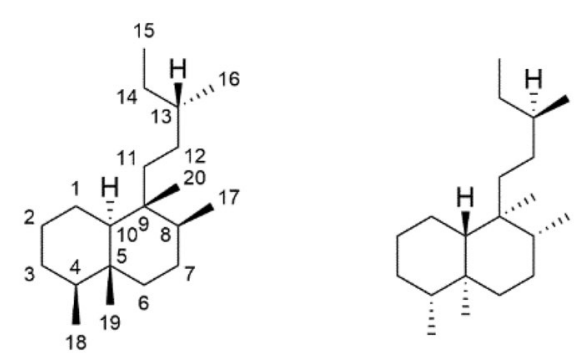

Clerodane diterpenoids

ent-Clerodane diterpenoids

Fig. 1 Skeletons of clerodane diterpenoids and ent-diterpenoids anti-inflammatory property (Fig. 2). Either in vitro or in vivo bioassays have been used to determine the antiinflammatory activity of clerodane diterpenoids. To better organize the review, the clerodane diterpenoids were introduced based on the anti-inflammatory bioassays (Table 1).

Lipopolysaccharide (LPS), a major constituent of the outer leaflet of Gram-negative bacterial outer membrane, is synthesized on the cytoplasmic membrane and transferred to the outer membranes [41, 42]. LPS treated murine microglial BV-2 cells are widely used for antiinflammatory drug screening and underlying mechanism investigation. Using the above mentioned model, 18 clerodane diterpenoids including scutebarbatine (14), scutebarbatine B (16), scutebatas B (17), scutebarbatine $X(\mathbf{1 8})$, ajugapantin $H(\mathbf{2 2})$, scutebaabaatine W (38), ajugapantins E (48), ajugapantins $F(49)$, ajugapantins G (50), ajugacumbin A (51), scutelapenes B (52), scutelapenes $C$ (53), scutelapenes $D(54)$, scutelapenes A (57), scutelapenes $E$ (58), ajugapantin $C$ (59), $\left(12 S, 2^{\prime \prime} S\right)-6 \alpha, 19$-diacetoxy-18-chloro-4 $\alpha$-hydroxy-12(2-methylbutanoyloxy)-neo-clerod-13-en-15,16-olide (60), and $6 \alpha, 19$-diacetoxy- $4 \alpha$-hydroxy- $1 \beta$-tigloyloxyneoclerod-12-en-15-oic acid methyl ester-16-aldehyde (61) were found to inhibit NO production [43-46]. Among them, compounds $\mathbf{2 2}, \mathbf{5 0}$ and $\mathbf{5 9}$ were discovered to downregulate iNOS and COX-2 expression [47].

LPS-stimulated murine-derived RAW264.7 macrophages have been widely used as a bioassay to investigate anti-inflammatory activity $[48,49]$. Using this model, 29 clerodane diterpenoids including 16-oxocleroda3,13-dien-15-oic acid (1), neoclerod-13Z-ene-3 $\alpha, 4 \beta, 15$ triol (4), 16-hydroxycleroda-3,13-dien-15,16-olide (7), 15-methoxypatagonic acid (12), 16-hydroxycleroda3,13-dien-16,15-olide-18-oic acid (13), scutebarbatine A (14), scutebarbatine Y (15), scutebarbatine B (16), $3 \beta, 4 \beta: 15,16$-diepoxy-13(16),14-clerodadiene (19), cathayanalactones A (20), cathayanalactones B (21), crotonolide $\mathrm{K}$ (25), furocrotinsulolide A acetate (26), 15,16-epoxy$3 \beta$-hydroxy-5(10),13(16),14-ent-halimatriene-17,(12S)olide (27), crotonolide F (28), scutebatin C (33), scutebarbatine W (34), scutebata P (35), scutebatin A (36), scutebatin B (37), $6 S$-crotoeurin $C(41)$, crotoeurin C (42), 3S-methoxylteucbin (44), 3R-methoxylteucbin (45), 19-acetyl-teuspinin (46), jamesoniellide Q (47), 11-hydroxyfruticolone (55), ajugacumbin $\mathrm{J}$ (56), and $6 \alpha$-acetoxyteuscordin (63) were found to inhibit NO production [50-59], and compounds 12 and 13 were further found to reduce IL- 6 , IL- $1 \beta$, and TNF- $\alpha$ production in dose-responsive manners [50].

Besides being deputed to host defense against microorganisms, neutrophils display fundamental roles both in inflammation and tissue damages [60]. 


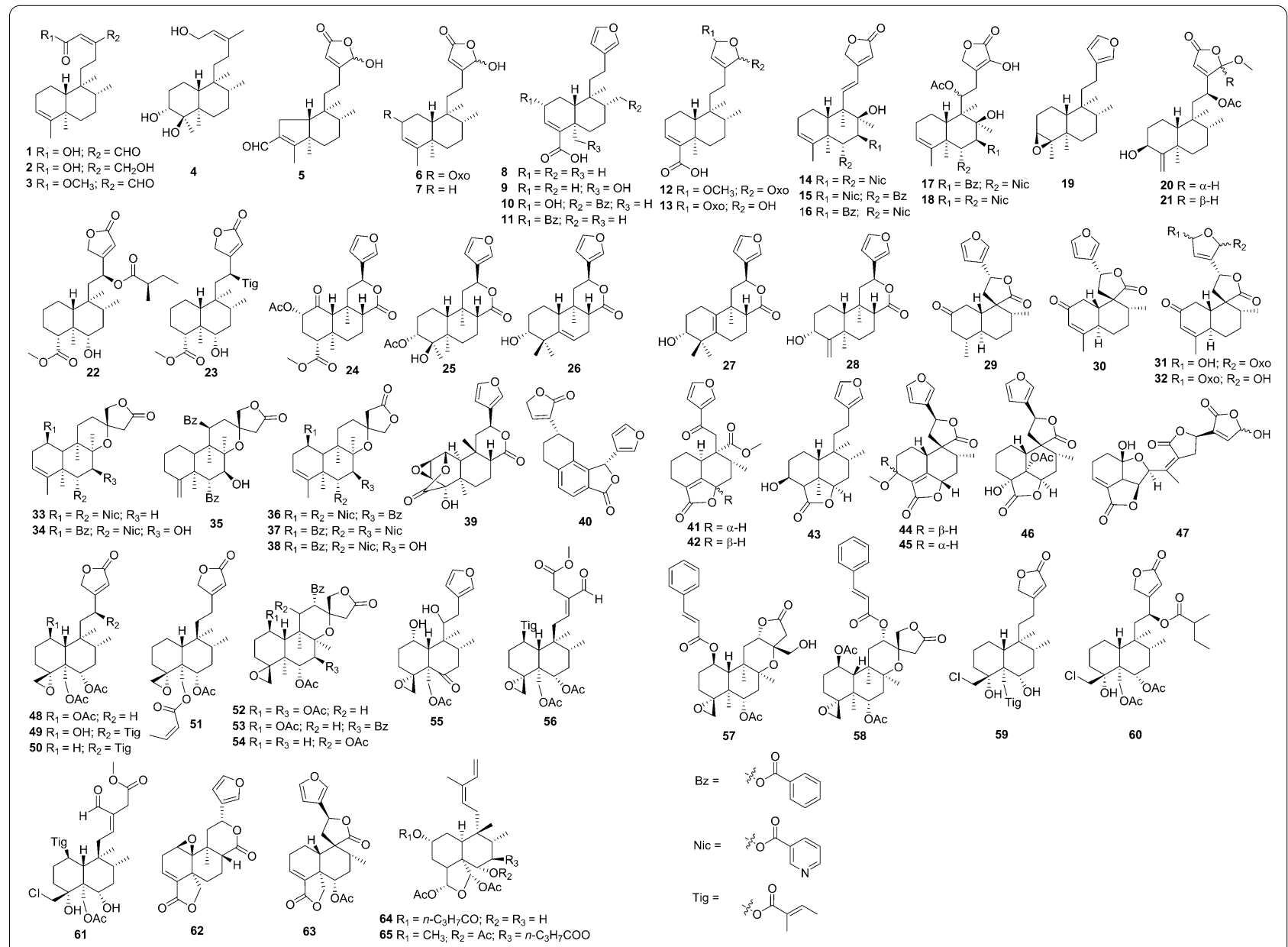

Fig. 2 Structures of clerodane diterpenoids with anti-inflammatory activity

$N$-formylmethionyl-leucyl-phenylalanine (fMLP) is a potent polymorphonuclear leukocyte chemotactic factor and a macrophage activator [61]. Neutrophils function as the first-line defense against invading bacteria fungi and protozoa [62], which are major effector cells to identify novel antibiotics and elucidate the pathogenesis behind neutrophil-mediated inflammatory disorders [63]. In fMLP/CB-stimulated human neutrophils, five clerodane diterpenoids including 16-hydroxycleroda-3,13(14)E-dien-15-oic acid (2), 16-oxocelroda-3,13(14)E-dien-15-oic acid methyl ester (3), (4-2)abeo-16-2,13Z-clerodadien-15,16-olide-3-al (5), 16-3,13Z-kolavadien-15,16-olide-2-one (6), and 16-hydroxycelroda-3,13-dien-15,16-olide (7) from the bark of Polyalthia longifolia var. pendula showed anti-inflammatory activity [64]. (-)-Hardwickiic acid (8) showed anti-inflammatory activity on neutrophils through suppressing both superoxide anion generation $\left(\mathrm{IC}_{50}=4.40 \pm 0.56 \mu \mathrm{M}\right)$ and elastase release $\left(\mathrm{IC}_{50}=3.67 \pm 0.20 \quad \mu \mathrm{M}\right) \quad[65] . \quad 16$-Hydroxycleroda-
3,13(14)E-dien-15-oic acid (2) was isolated from the same species, which concentration-dependently inhibited the generation of superoxide anion and the release of elastase in fMLP/CB-stimulated human neutrophils, with $\mathrm{IC}_{50}$ values of $3.06 \pm 0.20$ and $3.30 \pm 0.48 \mu \mathrm{M}$, respectively [66].

TPA (12-O-tetradecanoylphorbol 13-acetate) induces keratinocytes proliferation, TNF- $\alpha$ production, and the formation of leukotriene B4 (LTB4), to induce oxidative stress and cutaneous inflammation [67, 68]. Mice overexposed to TPA exhibit an inflammatory phenotype characterized by the increased ear thickness, macrophage infiltration, and epidermal hyperplasia [69]. In TPA-induced CD-1 auricular pavilion mice, two benzoyl ester clerodane diterpenoids, 15,16-epoxy- $8 \alpha$-(benzoyloxy)methyl$2 \alpha$-hydroxycelroda-3,13(16),14-trien-18-oic acid (10) and 15,16-epoxy-8 $\alpha$-(benzoyloxy)methyl-2-oxocelroda-3,13(16),14-trien-18-oic acid (11) isolated from the leaves and stems of Dodonaca polyandra, showed 


\section{Table 1 Clerodane diterpenoids with anti-inflammatory activity}

\begin{tabular}{|c|c|c|c|c|c|}
\hline No & Model/Method & Dose & Outcomes & Mechanisms & Ref \\
\hline 14 & & $30.9 \mu \mathrm{M}$ & & & [44] \\
\hline 16 & & $31.2 \mu \mathrm{M}$ & & & \\
\hline 17 & & $30.3 \mu \mathrm{M}$ & & & \\
\hline 18 & & $27.5 \mu \mathrm{M}$ & & & \\
\hline 38 & & $34.7 \mu \mathrm{M}$ & & & \\
\hline 48 & & $45.5 \pm 3.6 \mu \mathrm{M}$ & & & [47] \\
\hline 49 & & $34.0 \pm 3.2 \mu \mathrm{M}$ & & & \\
\hline 51 & LPS-induced murine microglial BV-2 & $48.5 \mu \mathrm{M}$ & Inhibited NO production & & {$[45]$} \\
\hline 52 & cells & $36.0 \pm 0.8 \mu \mathrm{M}$ & & Directly interacted and suppressed & [43] \\
\hline 53 & & $30 \mu \mathrm{M}$ & & & \\
\hline 54 & & $27.3 \pm 1.3 \mu \mathrm{M}$ & & & \\
\hline 57 & & $11.1 \pm 0.8 \mu \mathrm{M}$ & & & \\
\hline 58 & & $30 \mu \mathrm{M}$ & & & \\
\hline 60 & & $25.3 \mu \mathrm{M}$ & & & [46] \\
\hline 61 & & $27.2 \mu \mathrm{M}$ & & & [45] \\
\hline 22 & & $25.8 \pm 1.7 \mu \mathrm{M}$ & & Directly interacted and suppressed & [47] \\
\hline 50 & & $27.0 \pm 0.9 \mu \mathrm{M}$ & & iNOS and COX2 & \\
\hline 59 & & $20.2 \pm 2.0 \mu \mathrm{M}$ & & & \\
\hline 1 & LPS-induced RAW264.7 macrophages & $31.4 \mu \mathrm{M}$ & Inhibited NO production & & [57] \\
\hline 4 & & $25.49 \mu \mathrm{M}$ & & & [58] \\
\hline 7 & & $31.4 \mu \mathrm{M}$ & & & [57] \\
\hline 14 & & $26.3 \mu \mathrm{M}$ & & & [53] \\
\hline 15 & & $27.7 \mu \mathrm{M}$ & & & \\
\hline 16 & & $22.8 \mu \mathrm{M}$ & & & \\
\hline 19 & & $32.19 \mu \mathrm{M}$ & & & [54] \\
\hline 20 & & $22.92 \mu \mathrm{M}$ & & & [50] \\
\hline 21 & & $13.25 \mu \mathrm{M}$ & & & \\
\hline 25 & & $46.43 \mu \mathrm{M}$ & & & [54] \\
\hline 26 & & $31.99 \mu \mathrm{M}$ & & & \\
\hline 27 & & $48.85 \mu \mathrm{M}$ & & & \\
\hline 28 & & $42.04 \mu \mathrm{M}$ & & & \\
\hline 33 & & $35.6 \mu \mathrm{M}$ & & & [53] \\
\hline 34 & & $34.2 \mu \mathrm{M}$ & & & \\
\hline 35 & & $20.6 \mu \mathrm{M}$ & & & \\
\hline 36 & & $21.5 \mu \mathrm{M}$ & & & \\
\hline 37 & & $20.2 \mu \mathrm{M}$ & & & \\
\hline 41 & & $1.2 \mu \mathrm{M}$ & & & [51] \\
\hline 42 & & $1.6 \mu \mathrm{M}$ & & & \\
\hline 44 & & $0.82 \mu \mathrm{M}$ & & & [91] \\
\hline 45 & & $0.54 \mu \mathrm{M}$ & & & \\
\hline 46 & & $21.9 \mu \mathrm{M}$ & & & [52] \\
\hline 47 & & $45.1 \mu \mathrm{M}$ & & & [59] \\
\hline 55 & & $39.3 \mu \mathrm{M}$ & & & [56] \\
\hline 56 & & $36.2 \mu \mathrm{M}$ & & & [55] \\
\hline 63 & & $22.4 \mu \mathrm{M}$ & & & [52] \\
\hline 12 & & $35.35 \mu \mathrm{M}$ & \multirow{2}{*}{$\begin{array}{l}\text { Inhibited NO, IL-6, IL-1 } 1 \beta \text { and TNF-a pro- } \\
\text { duction in a dose-responsive manner }\end{array}$} & & [50] \\
\hline 13 & & $17.49 \mu \mathrm{M}$ & & & \\
\hline
\end{tabular}


Table 1 (continued)

\begin{tabular}{|c|c|c|c|c|c|}
\hline No & Model/Method & Dose & Outcomes & Mechanisms & Ref \\
\hline 2 & \multirow[t]{7}{*}{ fMLP/CB induced neutrophils } & $4.40 \pm 0.83 \mu \mathrm{M}$ & \multirow[t]{5}{*}{ Suppressed superoxide generation } & & [64] \\
\hline 3 & & $1.81 \pm 0.27 \mu \mathrm{M}$ & & & \\
\hline 5 & & $13.00 \pm 1.77 \mu \mathrm{M}$ & & & \\
\hline 6 & & $23.95 \pm 5.36 \mu \mathrm{M}$ & & & \\
\hline 7 & & $9.59 \pm 3.55 \mu \mathrm{M}$ & & & \\
\hline 8 & & $\begin{array}{l}4.40 \pm 0.56 \mu \mathrm{M} \\
3.67 \pm 0.20 \mu \mathrm{M}\end{array}$ & \multirow[t]{2}{*}{$\begin{array}{l}\text { Inhibited superoxide anion generation } \\
\text { and elastase release }\end{array}$} & & [65] \\
\hline 2 & & $3.06 \pm 0.20 \mu \mathrm{M}$ & & $\begin{array}{l}\text { Attenuated the phosphorylation of } \\
\text { AKT and p38 MAPK }\end{array}$ & [66] \\
\hline 9 & \multirow{5}{*}{$\begin{array}{l}\text { TPA-induced CD-1 auricular pavilion } \\
\text { mouse ear edema }\end{array}$} & $0.25,0.5,1 \mathrm{mg} / \mathrm{ear}$ & Reduced edema to $64 \%$ & & [71] \\
\hline 10 & & $0.10 \mathrm{mg} / \mathrm{ear}$ & \multirow{2}{*}{$\begin{array}{l}\text { exhibited } 70-76 \% \text { Inhibition of inflam- } \\
\text { mation }\end{array}$} & & [70] \\
\hline 11 & & $0.39 \mathrm{mg} / \mathrm{ear}$ & & & \\
\hline 40 & & 200 mg/kg & Dose-dependently inhibited ear edema & & [73] \\
\hline 62 & & $0.50 \mu \mathrm{g} / \mathrm{ear}$ & Inhibited ear edema & & [72] \\
\hline 10 & TPA-induced acute mouse ear edema & $2.03 \mu \mathrm{g} / \mathrm{ear}$ & $\begin{array}{l}\text { Inhibited IL-1 } \beta \text { production, reduced ear } \\
\text { thickness, IL-6 and myeloperoxidase } \\
\text { accumulation }\end{array}$ & & [81] \\
\hline 24 & \multirow[t]{5}{*}{$\begin{array}{l}\text { carrageenan-induced paw edema } \\
\text { in rats }\end{array}$} & $50-200 \mathrm{mg} / \mathrm{kg}$ & $\begin{array}{l}\text { Dose-dependently inhibited paw } \\
\text { edema. }\end{array}$ & & [73] \\
\hline 30 & & 200 mg/kg & $\begin{array}{l}\text { Inhibited paw edema and cotton pellet } \\
\text { granuloma }\end{array}$ & & [77] \\
\hline 43 & & $20 \mathrm{mg} / \mathrm{kg}$ & Inhibited inflammation in rat paw & & [78] \\
\hline 64 & & $0.5,2.5 \mathrm{mg} / \mathrm{kg}$ & Reduced paw edema & & [76] \\
\hline \multicolumn{5}{|l|}{65} & \\
\hline 24 & Carrageenan-induced pleurisy in rats & $10 \mathrm{mg} / \mathrm{kg}$ & $\begin{array}{l}\text { Inhibited LTB4 production in exudates } \\
\text { and phlogistic process in lung }\end{array}$ & & [79] \\
\hline 31 & \multirow{2}{*}{$\begin{array}{l}\text { Teleocidin induced mouse ear inflam- } \\
\text { mation }\end{array}$} & $5.6 \mu \mathrm{g} / \mathrm{ear}$ & \multirow{2}{*}{$\begin{array}{l}\text { Inhibited tropical inflammation in } \\
\text { mouse ear }\end{array}$} & & [92] \\
\hline 32 & & $3.0 \mu \mathrm{g} / \mathrm{ear}$ & & & \\
\hline 39 & $\begin{array}{l}\text { Indomethacin-induced gastric ulcer } \\
\text { in rats }\end{array}$ & $50 \mathrm{mg} / \mathrm{kg}$ & $\begin{array}{l}\text { Downregulated PGE2, IL-4, IL-10, VEGF, } \\
\text { and EGF }\end{array}$ & & [83] \\
\hline 7 & DSS/OAM induced IBD mice & $1.6,6.4 \mathrm{mg} / \mathrm{kg}$ & Reduced iNOS, COX2 expression & Reduced NF-KB gene expression & [85] \\
\hline 29 & Dextran- or histamine-induced edema & $50 \mathrm{mg} / \mathrm{kg}$ & Reduced edema & & [80] \\
\hline \multirow[t]{2}{*}{24} & A23187-induced LTB4 biosynthesis & $1 \mu \mathrm{M}$ & $\begin{array}{l}\text { Dose-dependently inhibited LTB4 } \\
\text { biosynthesis }\end{array}$ & & [79] \\
\hline & Zymosan-induced peritonitis & $10 \mathrm{mg} / \mathrm{kg}$ & $\begin{array}{l}\text { Inhibited myeloperoxidase activity, } \\
\text { LTC4 production, cell infiltration, and } \\
\text { vascular permeability in the perito- } \\
\text { neal cavity, but not the production } \\
\text { of PGE2 }\end{array}$ & & \\
\hline
\end{tabular}

maximum inhibition of inflammation (70-76\%) at the dose of 0.10 and $0.39 \mathrm{mg} /$ ear, respectively [70]. Hautriwaic acid (9), isolated from Dodonaca viscosa leaves, relieved ear edema in TPA-induced mice at the dose of $0.25,0.5$, and $1.0 \mathrm{mg} / \mathrm{ear}(60.2,70.2$ and $87.1 \%$ inhibition, respectively) [71]. Tehuanins G (11), isolated from the aerial parts of Salvia herbacea, exhibited the comparable effect as that of indomethacin in TPA-induced mice [72]. Tillifodiolide (40), isolated from Salvia tiliifolia, dose-dependently decreased ear edema in TPA-induced ear edema [73].
Carrageenan is a phlegmatic agent for rat and mice paw edema [74]. Carrageenan-induced paw edema has been described as a local and acute inflammatory process [75]. Caseargrewiin F (64) and casearin B (65) $(0.5 \mathrm{mg} / \mathrm{kg})$ showed a reduction of paw edema in the carrageenaninduced rats, compared to that of indomethacin [76]. Trans-dehydrocrotonin (30), isolated from the barks of Croton cajucara (Euphorbiaceae), alleviated carrageenaninduced paw edema in rats [77]. Tillifodiolide (40), isolated from Salvia tiliifolia Vahl (Lamiaceae), dosedependently inhibited paw edema in the carrageenan 
test [73]. Nepetolide (43), a tricyclic clerodane-type diterpenoid isolated from Nepeta suavis, reduced carrageenan-induced paw edema at the dose of $20 \mathrm{mg} / \mathrm{kg}$ [78]. In carrageenan-induced pleurisy, salvinorin A (24) suppressed LTB4 production in exudates, and reduced the phlogistic process in lung [79].

In teleocidin induced mouse ear inflammation, cajucarinolide (31) and isocajucarinolide (32), two clerodane diterpenoids isolated from the cortices of Croton cajucara (Euphorbiaceae), inhibited inflammation in mouse ear at the dosage of 5.6 and $3.0 \mu \mathrm{g} / \mathrm{ear}$ [80].

In TPA-induced acute and chronic mouse ear edema models, polyandric acid A (10) from the Australian medicinal plant Dodonaea polyandra, inhibited IL-1 $\beta$ and IL-6 production, ear thickness and myeloperoxidase (MPO) accumulation [81].

Stomach illnesses are common health problems worldwide [82]. In indomethacin-induced gastric ulcer rats, epoxy clerodane diterpene $(5 R, 10 R)-4 R, 8 R$-dihydroxy$2 S, 3 R: 15,16$-diepoxycleroda-13(16),17,12S,18,1S-dilactone (39), isolated from Tinospora cordifolia, showed a gastroprotective effect. Epoxy clerodane diterpene reversed indomethacin-induced increases of ulcer index (UI) and MPO activity, downregulation of PGE2, and decreases of IL-4 and IL-10. Pre-administration of the specific COX-1 inhibitor and nonspecific NOS inhibitor totally blocked the ulcer-healing activity of epoxy clerodane diterpene, indicating the involvement of PGE2 and NOS in the ulcer healing activity of epoxy clerodane diterpene [83].

IBD is caused by microbial infiltration or immunocyte attack, which is a general term for ulcerative colitis and Crohn's disease [84]. The treatment of IBD remains unsolved. By using dextran sulfate sodium (DSS)/azoxymethane (AOM) induced IBD mouse model, 16-hydroxycleeroda-3,13-dien-15,16-olide (7), isolated from Polyalthia longifolia var. pendula Linn. (Annonaceae), was demonstrated to ameliorate the inflammatory symptoms [85].

Dextran-induced edema induces an anaphylactoid reaction, which is widely used as an acute experimental model of inflammation [86]. Trans-crotonina showed inhibitory effect at the rate of $31.9 \%$ in dextran-induced edema [80]. Histamine is known to increase vascular permeability [87]. Histamine-induced edema is widely used to screen anti-inflammatory drugs [88]. Trans-crotonina showed inhibitory effect in histamine-induced edema [80].

Arachidonic acid-derived LTs are highly related to inflammatory diseases such as asthma, allergic rhinitis and cardiovascular disease [89]. Calcium ionophore A23187-stimulated peritoneal macrophages (PM) were used as an in vitro model to evaluate SA-indcued production of LT [90]. SA concentration-dependently inhibited LTB4 biosynthesis in isolated PM, and suppressed myeloperoxidase activity, cell infiltration, LTC4 production, and vascular permeability, in the peritoneal cavity, but not the production of PGE2 [79].

In summary, a total of 65 clerodane diterpenoids were reported with potential anti-inflammatory property. While, their anti-inflammatory activity was only evaluated on either in vitro cellular models or in vivo animal models, no clinical study was carried out till now. In the future, clinical trials must be performed to authenticate the therapeutic effect of clerodane diterpenoids in alleviating inflammatory responses.

\section{Comparison of drug-likeness of anti-inflammatory clerodane diterpenoids with marketed drugs}

SwissADME is a tool provided by the Swiss institute of Bioinformatics [93], which was used to predict molecular descriptors of the above summarized clerodane diterpenoids. To better summarize the drug-likeness properties of all these compounds, the following descriptors were described, inluding molecular weight (MW), number of hydrogen bond acceptors (HBA) and donors (HBD), number of stereogenic centers, and number of rotatable bonds (RB). The fraction of sp3 carbon $\left(\mathrm{Fsp}^{3}\right)$ is defined as the ratio of $\mathrm{sp} 3$ hybrid carbon to the total carbon number. The fraction of carbon and aromatic heavy atoms (Far) is the ratio of the number of aromatic heavy atoms to the total number of heavy atoms [94].

The predicted results were shown in Additional file 1: Table S1, which were grouped according to the previously described categories. Absorption, distribution, metabolism, and excretion (ADME) are critical factors in drug development [95], drug similarity and medicinal chemistry friendliness. Additional file 1: Table S2 showed the physicochemical properties, molecular polar surface area (PSA), pharmacokinetics, LogS and iLOGP, as well as bioavailability characteristics of clerodane diterpenoids (Supplementary Material). Especially for LogP [96] and LogS [97], more than one algorithm was used.

To better compare those anti-inflammatory clerodane diterpenoid derivatives with marketed drugs, the MW, HBA, HBD [98], Log P, PSA, RB, and stereogenic centers were evaluated; and the marketed drugs were divided into natural products, natural products derivatives, natural product type macrocycles, polycyclic compounds, synthetic compounds, and assumed synthetic compounds $[99,100]$ (Fig. 3).

\section{Size: molecular weight}

Lopinski's rule of five defined the suitable traditional therapeutic agents [101], including less than 500 Da molecular 


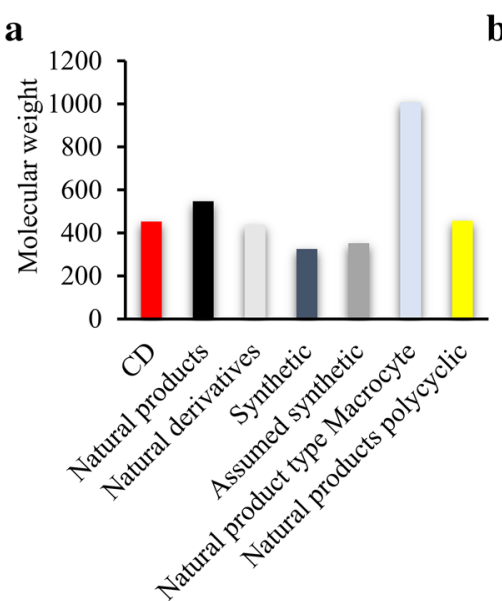

d

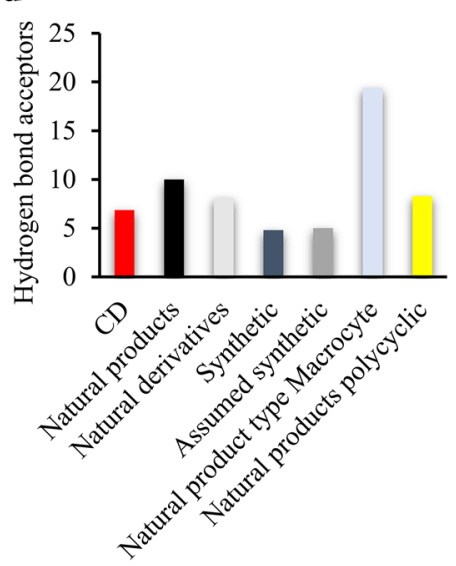

f

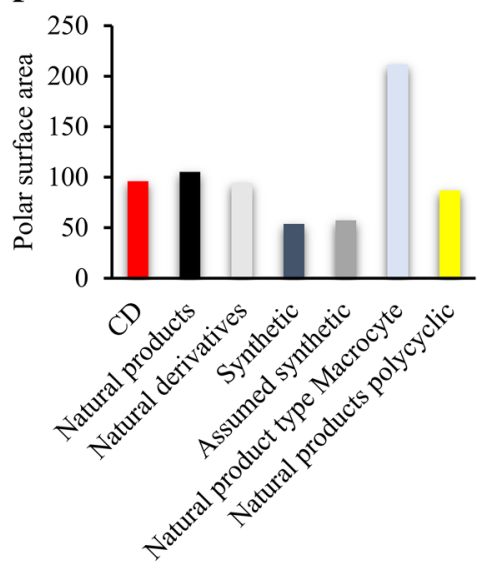

b

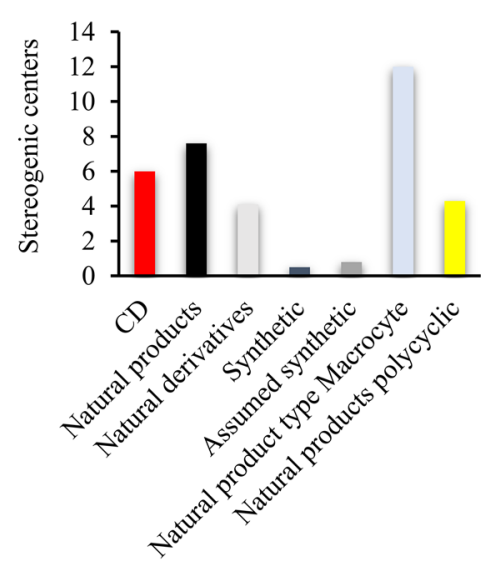

$\mathbf{e}$

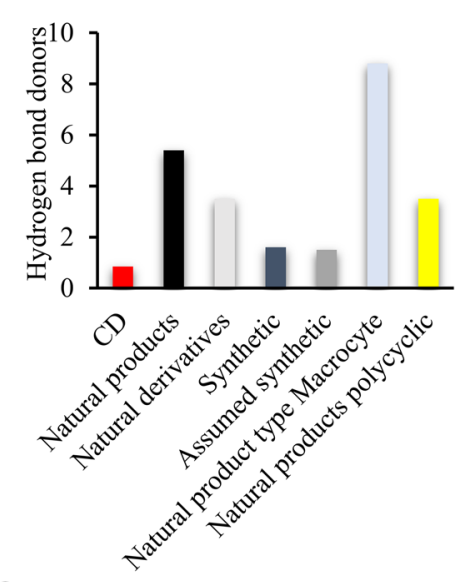

g

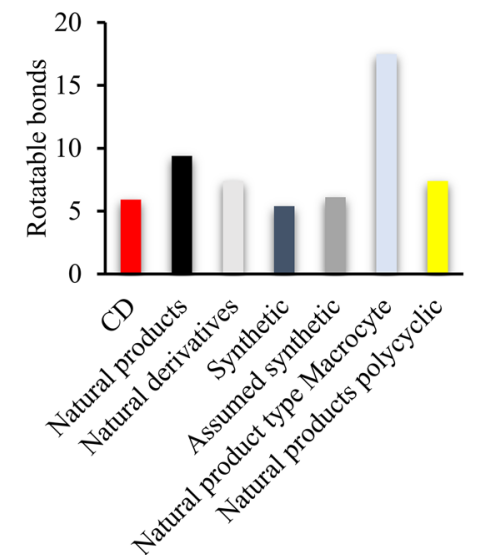

Fig. 3 Mean values of MW (a), stereogenic centers (b), LogP (c), HBA (d), HBD (e), PSA (f), RB (g). Anti-inflammatory clerodane diterpenoids (CD) (red), synthetic (dark blue), assumed synthetic (dark grey), natural products (black), natural derivatives (light grey), natural product type macrocyte (light blue), natural products polycyclic (yellow)

mass, no more than $10 \mathrm{HBA}$, no more than $5 \mathrm{HBD}$, and an octanol-water partition coefficient $\log \mathrm{P}$ not great than 5. According to the SwissADME results, the mean MW for the anti-inflammatory clerodane diterpenoids

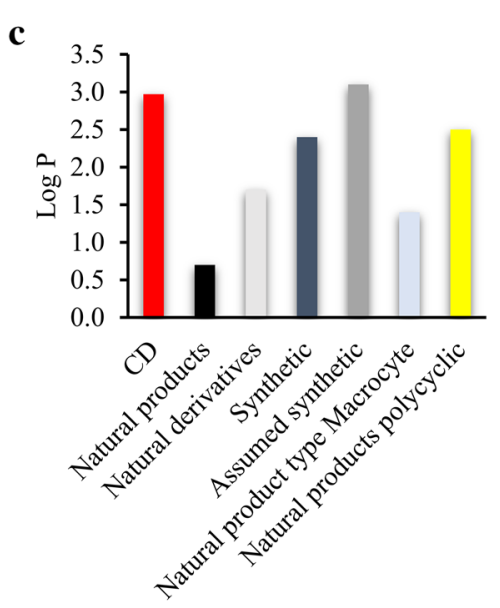

was 452.4 Da (Fig. 3a). Most NSAIDs [102], and 61\% of clerodane diterpenoids are with the MW less than $500 \mathrm{Da}$, which match to Lopinski's rule of five. 


\section{Chirality: number of stereogenic centers}

The number of stereocenters has an important impact on the chiral structure and self-assembly of molecular aggregates. The number of stereogenic centers in clerodane diterpenoids was 6 , which was comparable with those of natural products, natural products derivatives, natural product type macrocycles, polycyclic compounds, synthetic compounds, and assumed synthetic compounds (Fig. 3b). The natural product type macrocycle have the highest value of the stereogenic center, 12. For the synthesis of chemical compounds, more chiral centers causes more difficulty and higher cost of synthesis [99]. The number of stereogenic centers in the anti-inflammatory clerodane diterpenoid derivatives meets the standards for new drug development.

\section{Polarity: PSA and HBD/HBA}

A major challenge in drug discovery is the prediction of permeability, which, along with solubility, governs the skill of drugs and candidates transport across the gastrointestinal membrane and thus contributes to the overall exposure in systemic circulation and brain penetration. PSA, a descriptor defined as the sum of surfaces of nitrogen or oxygen atoms, plus hydrogen atoms attached to oxygen or nitrogen atoms in a molecule, has been widely used with a discrete success to model permeability and other ADME-related properties [103]. The topological PSA (TPSA) is often implemented in the drug-discovery pipeline [104]. However, the limitation of PSA should be considered. PSA does not take into account the contribution of polarity arising from electronegative atoms in drugs besides nitrogen and oxygen. And the different electronegativity of the atoms of the molecule produces a redistribution of the electron density that in principle involves the entire molecule. PSA is highly correlated with hydrogen bonding (HB. In principle, quantum mechanics calculations could also improve the description of HBA and HBD properties and the polarity of the molecules [105].

The PSA mean values were $96.1 \AA^{2}$ for clerodane diterpenoids, $86.9 \AA^{2}$ for polycyclic drugs, and $105.3 \AA^{2}$ for natural products. Additionally, the HBA/HBD and PSA values of anti-inflammatory clerodane diterpenoids are positively correlated with their MW (Figs. 3d-f and 4). According to the rule of 5, most of the anti-inflammatory clerodane diterpene derivatives might have good oral absorption.

\section{Molecular flexibility: rotatable bonds and aromatic character}

RBs are the number of bonds that allow free rotation, excluding those adjacent to triple bonds, connect

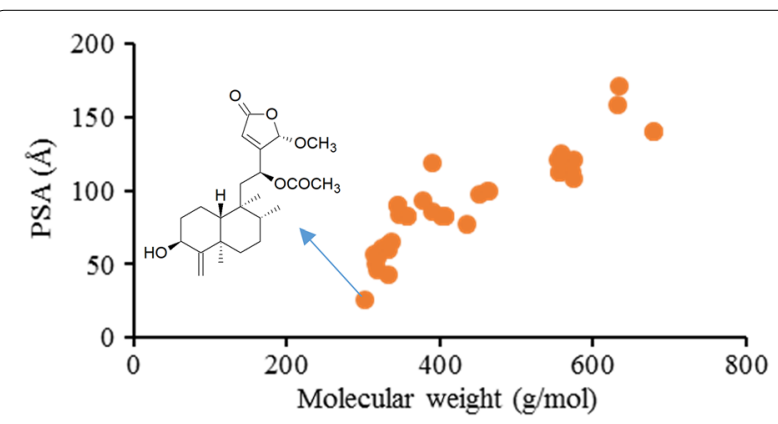

Fig. 4 PSA values of the anti-inflammatory clerodane diterpenoid derivatives vs molecular weight (MW)

hydrogen or halogen atoms, or in rings containing less than five single bonds [106]. The amide C-N bond is excluded due to its high rotational energy barrier. Reduced molecular flexibility (less RBs), and low PSA or total HB imply good oral bioavailability [107]. The number and percentage of RBs are descriptors for the biological effect of molecules. Compounds with less than 7 RBs exhibited oral bioavailability of more than $20 \%$ [108]. The increased RBs number interrupts the permeation rate to reduce oral bioavailability.

The mean numbers of RBs for the summarized clerodane diterpenoids, the polycyclic compounds, natural products, natural product derivatives, and synthetic drugs were 5.92, 7.4, 9.4, 7.4, and 5.4, respectively (Fig. 3g). The less RBs for the clerodane diterpenoids indicated a good permeation rate. The summarized clerodane diterpenoids have a mean $\mathrm{Fsp}^{3}$ of 0.64 because they possess an aromatic character.

\section{Lipophilicity: LogP}

$\log \mathrm{P}$ is normally determined in the hit to lead stage of drug discovery [109]. Lipophilicity of a drug is the ratio between its concentrations at the equilibrium in 1-octanol and water, commonly described as LogD [110]. The partition coefficient $(\mathrm{P})$ is the specific distribution coefficient (D) at any given $\mathrm{pH}$ (typically neutral) [111].

The $\log \mathrm{P}$ values of the anti-inflammatory clerodane diterpenoids are different by using different predicted method on Swiss ADME. Among all $\log \mathrm{P}$ index, MLOGP is the most discrepant one (Fig. 5). Compare to the synthetic compounds, assumed synthetic compounds, natural products, natural derivatives, natural product macrocycles, and natural products polycyclic, the $\log P$ value of the clerodane diterpenoids (3.0) is higher, indicating lower oral bioavailability. 


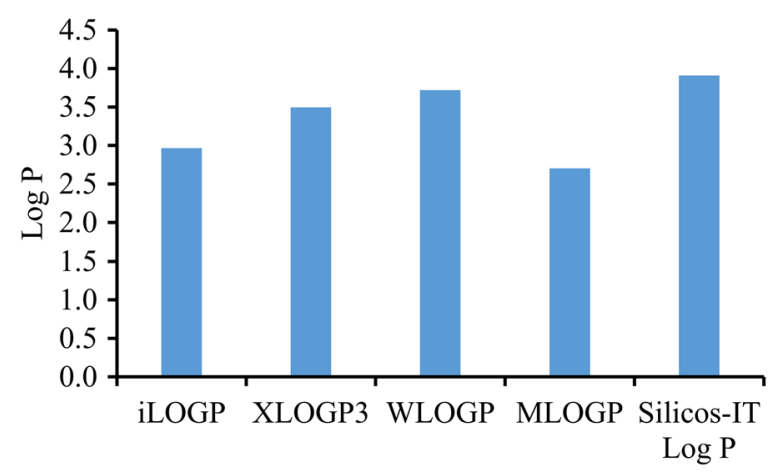

Fig. 5 Mean LogP values of the anti-inflammatory clerodane diterpenoids calculated by different methods

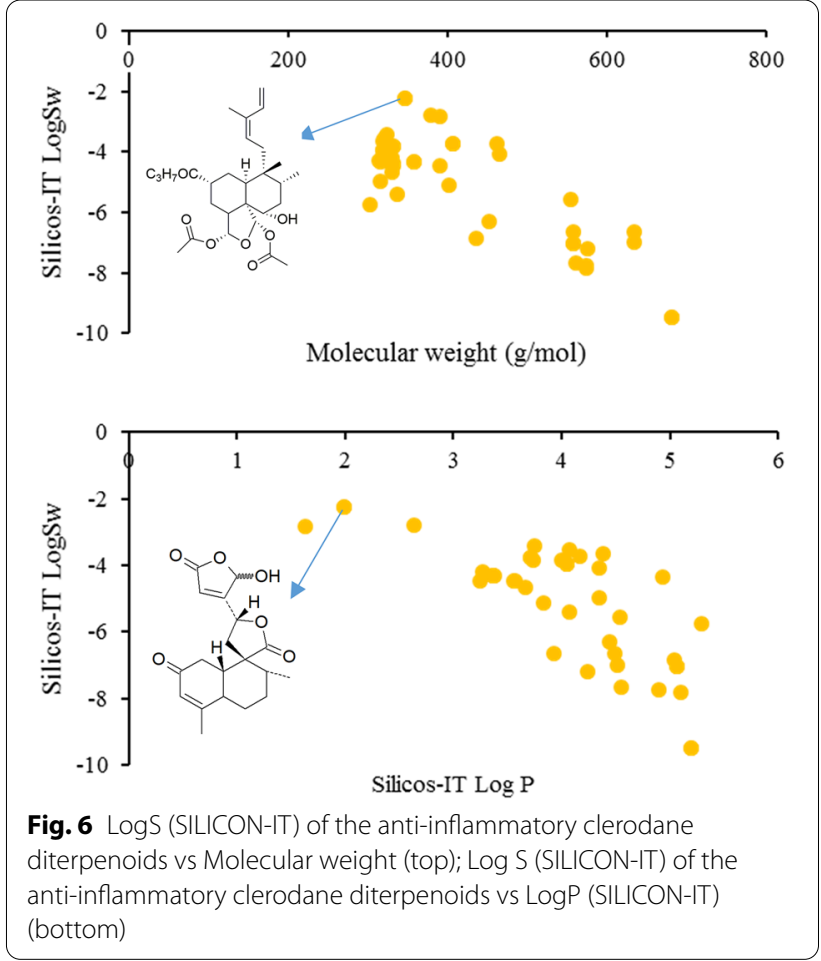

\section{Solubility: LogS}

If the solubility and rate of dissolution are low, an enterally administered drug will mostly be excreted [112]. Solubility of a compound is commonly expressed as $\operatorname{logS}$, where $S$ is the concentration of the compound in a saturated aqueous solution (mol/L). $85 \%$ of drugs have $\log S$ values between -1 and -5 and virtually none has value below -6 [113].

The aqueous solubility of clerodane diterpenoids is negatively correlated with MW (Fig. 6). Most of the anti-inflammatory clerodane diterpenoids have poor water solubility. Only a few examples showed the Log $S$ values greater than -4 , such as casearin $B(65)$ and isocajucarinolide (32), which might have great potential to be developed as drugs.

\section{Compliance of clerodane diterpenoids with the rules of drug-likeness}

The " 5 Rules" has been widely used as the first filter to eliminate potential drug candidates with poor oral bioavailability [107]. According to different compliance rules, the biophysical and chemical properties and molecular descriptors of the anti-inflammatory clerodane diterpenoids were evaluated. Most of them possess good drug-likeness (green in Additional file 1: Table S3).

\section{Trends on the PK behavior of clerodane diterpenoids}

Besides efficacy and toxicity, poor pharmacokinetics and bioavailability always cause drug development failures. The two pharmacokinetic behaviors, gastrointestinal absorption and brain entry, are critical at different stages of the drug discovery process. BOILED Egg, an accurate predictive model, was developed by calculating the lipophilicity and polarity of small molecules [114]. It is widely used in the filtering of chemical libraries and the evaluation of drug candidates [115].

Based on the predicted results, about $80 \%$ of antiinflammatory clerodane diterpenoids are more likely to be absorbed in the gastrointestinal (GI), mainly due to their lower MW (Fig. 7a). Among them, 53 clerodane diterpenoids have higher GI absorption, and 34 ones have a high probability as P-gp substrates (Fig. 7a).

The brain capillary endothelium for the blood-brain barrier (BBB) to exclude 100\% of large-molecule neurotherapeutics and more than $98 \%$ of all small-molecule drug. $\mathrm{BBB}$ is the key issue in brain drug development [116]. Most of the anti-inflammatory clerodane diterpenoids have a low probability to cross the BBB (Fig. 7b). Among them, ten compounds are with potential ability to be P-gp substrates (Additional file 1: Table S5).

The possibility of clerodane diterpenoids as inhibitors of one of the five major isoforms of CYP450 (CYP1A2, CYP2C9, CYP2C19, CYP2D6, and CYP3A4) was predicted by SwissADME (Additional file 1: Table S4) [117, 118]. The anti-inflammatory clerodane diterpenoids are potent CYP450 enzyme inhibitors, especially for the CYP3A4 (Fig. 8).

\section{Conclusions}

Clerodane diterpenoids are secondary metabolites widely distributed in plants, fungi, bacteria, and marine sponges. In this review, 65 anti-inflammatory clerodane diterpenoids were reviewed based on their chemical structures 
$\mathbf{a}$

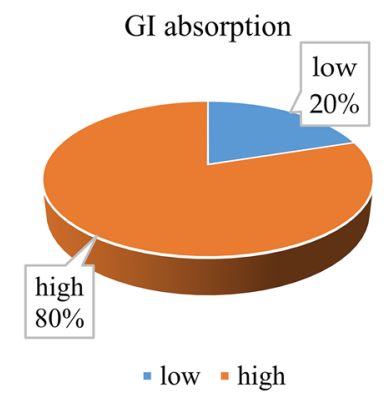

P-gp substrate

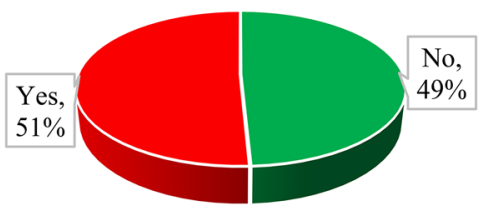

- No - Yes b

BBB permeant

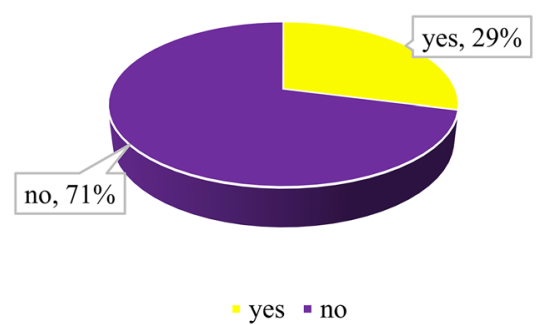

Fig. 7 a Gl absorption for the identified anti-inflammatory clerodane diterpenoids (left pie chart). Anti-inflammatory clerodane diterpenoids with high Gl absorption were classified accordingly to its P-gp substrate (right pie chart). (B) BBB permeability of the identified clerodane diterpenoids

and pharmacological models. The knowledge system of chemistry and bioactivity of clerodane diterpenoids continues to grow rapidly in recent years. Based on the current review, ent-clerodane diterpenoids always possess better anti-inflammatory activity than clerodane diterpenoids. And a lactone ring between C-18 and C-19 is essential for the anti-inflammation activity of clerodane diterpenoids. Although lots of evidence suggested the anti-inflammatory property of clerodane diterpenoids, the clinical application of these molecules as anti-inflammatory therapy is still far away. Till now, only evidence from in vitro cellular models or in vivo animal models was available. Clinical trials are necessary to authenticate the therapeutic effect of clerodane diterpenoids in alleviating inflammatory responses. The efficacy of these clerodane diterpenoids is not potent enough; thus, further phytochemical isolation and structural optimization are needed to enhance activity, improve specificity and reduce toxicity. Moreover, virtual docking and/or chemical biology studies should be carried out to identify the potential targets for the anti-inflammatory clerodane diterpenoids. The underlying mechanisms involved in the anti-inflammatory activity should be disclosed by pharmacological investigation.

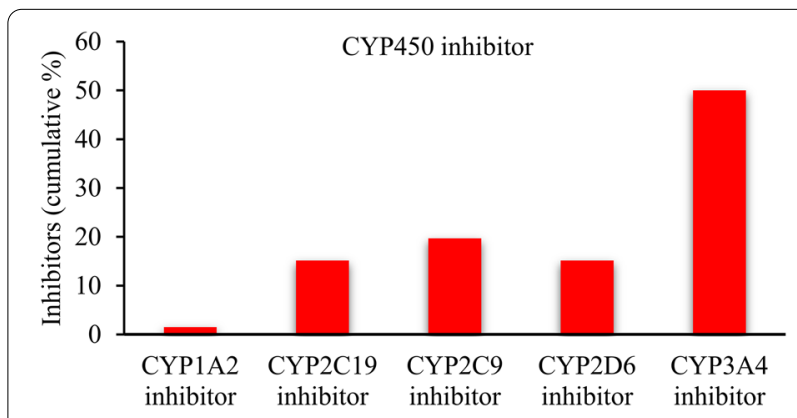

Fig. 8 CYP450 enzyme inhibitors of the identified anti-inflammatory clerodane diterpenoid derivatives
Online bioinformatics tool SwissADME provides a lot of predicted data of a compound, such as molecular descriptors, the biophysiochemical properties, and the PK parameters. A serious of drug-likeness analyses could be performed to better understand its properties, such as MW, $\log$ P, $\log$, PSA, HBA, HBD, RBs, and number of stereogenic centers. For natural medicine investigation, the combination of bench research and bioinformatics prediction tools could be an effective and economical approach to discover new anti-inflammatory drugs. Regarding to the anti-inflammatory clerodane diterpenoids, future chemical and biological researches will be very bright and challenging, and they have a huge therapeutic application prospect.

\section{Supplementary information}

Supplementary information accompanies this paper at https://doi. org/10.1186/s13020-020-00407-w.

Additional file 1: Table S1.Molecular descriptors of anti-inflammation clerodane diterpenoids. Table S2. Biophysiochemical properties of anti-inflammation clerodane diterpenoids.Table S3, Violations of druglikeness rules by the anti-inflammation clerodane diterpenoids. For each compound, the type of violations of each rule was described. Table S4 .Absorption and Metabolism parameters of anti-inflammation clerodane diterpenoids.

\section{Abbreviations}

ADME: Absorption, distribution, metabolism, and excretion; BBB: Blood-brain barrier; ECD: Epoxy clerodane diterpene; fMLP: N-formylmethionyl-leucyl-phenylalanine; COX: Cyclooxygenase; DSS: Dextran sulfate sodium; GI: Gastrointestinal; HBA, HBD: Hydrogen bond acceptors and donors; HA: Hautriwaic acid; IBD: Inflammatory bowel disease; IL-1 $\beta$ : Interleukin-1 $\beta$; LTs: Leukotrienes; LTB4: Leukotriene B4; LTC4: Leukotriene C4; LPS: Lipopolysaccharide; MW: Molecular weight; MPO: Myeloperoxidase; NOS: Nitric oxide synthase; NO: Nitric oxide; NOS: Nitric oxide synthase; NSAID and SAID: Nonsteroidal anti-inflammatory drugs (NSAID) and glucocorticoids; PM: Peritoneal macrophages; PGE2: Prostaglandin E2; PSA: Polar surface area; RBs: Rotatable bonds; TNF-a: Tumor necrosis factor-a; TPA: 12-O-tetradecanoylphorbol-13-acetate; Th1:T helper type 1;TPSA: Topological polar surface area; UI: Ulcer index.

\section{Acknowledgements}

Not applicable. 


\section{Authors' contributions}

All authors contributed in the preparation of this manuscript. ZLF made contributions to acquisition, compiling and analysis of the data, writing this manuscript. JC and QWZ were responsible for design and revising of this manuscript. LGL is the corresponding author and the guarantor. All authors read and approved the final manuscript.

\section{Funding}

This research was funded by the Science and Technology Development Fund, Macau SAR (File no. 0031/2019/A1), the National Natural Science Foundation of China (81872754), and University of Macau (File no. MYRG2017-00109-ICMS and MYRG2018-00037-ICMS).

\section{Availability of data and materials}

All available data and material can be accessed.

\section{Ethics approval and consent to participate}

Not applicable.

\section{Consent for publication}

The authors consent for the publication of this review.

\section{Competing interests}

All authors declare that they have no competing interests.

Received: 21 June 2020 Accepted: 26 November 2020

Published online: 09 December 2020

\section{References}

1. Miller $\mathrm{AH}$, Raison $\mathrm{CL}$. The role of inflammation in depression: from evolutionary imperative to modern treatment target. Nat Rev Immunol. 2016;16(1):22-34.

2. Amor S, Puentes F, Baker D, Van Der Valk P. Inflammation in neurodegenerative diseases. Immunology. 2010;129(2):154-69.

3. Chung HY, Cesari M, Anton S, Marzetti E, Giovannini S, Seo AY, et al. Molecular inflammation: underpinnings of aging and age-related diseases. Ageing Res Rev. 2009;8(1):18-30.

4. Wright HL, Moots RJ, Bucknall RC, Edwards SW. Neutrophil function in inflammation and inflammatory diseases. Rheumatology. 2010;49(9):1618-31.

5. Danesh J, Whincup P, Walker M, Lennon L, Thomson A, Appleby P, et al. Low grade inflammation and coronary heart disease: prospective study and updated meta-analyses. BMJ. 2000;321(7255):199-204.

6. Candore G, Caruso C, Jirillo E, Magrone T, Vasto S. Low grade inflammation as a common pathogenetic denominator in age-related diseases: novel drug targets for anti-ageing strategies and successful ageing achievement. Curr Pharm Des. 2010;16(6):584-96.

7. Lin LG, Jee JH, Buras ED, Yu KJ, Wang RT, Smith CW, et al. Ghrelin receptor regulates adipose tissue inflammation in aging. Aging. 2016;8(1):178-91.

8. Raghavendra V, Tanga FY, DeLeo JA. Complete Freunds adjuvantinduced peripheral inflammation evokes glial activation and proinflammatory cytokine expression in the CNS. Eur J Neurosci. 2004;20(2):467-73.

9. Wellen KE, Hotamisligil GS. Obesity-induced inflammatory changes in adipose tissue. J Clin Invest. 2003;112:1785-8.

10. Hotamisligil GS, Shargill NS, Speigelman BM. Adipose expression of tumor necrosis factor-alpha: direct role in obesity-linked insulin resistance. Science. 1993;259(5091):87-91.

11. Ruddle NH. Tumor necrosis factor (TNF-a) and lymphotoxin (TNF- $\beta$ ). Curr Opin Immunol. 1992;4(3):327-32.

12. Defer N, Azroyan A, Pecker F, Pavoine C. TNFR1 and TNFR2 signaling interplay in cardiac myocytes. J Biol Chem. 2007;282(49):35564-73.

13. Lukens JR, Gross JM, Kanneganti TD. IL-1 family cytokines trigger sterile inflammatory disease. Front Immunol. 2012;3:315.

14. Banerjee M, Saxena M. Interleukin-1 (IL-1) family of cytokines: role in type 2 diabetes. Clin Chim Acta. 2012;413(15-16):1163-70.

15. Jones $\mathrm{LL}$, Vignali DA. Molecular interactions within the IL-6/IL-12 cytokine/receptor superfamily. Immunol Res. 2011;51(1):5.
16. Fiorentino DF, Zlotnik A, Mosmann T, Howard M, O'garra A. IL-10 inhibits cytokine production by activated macrophages. J Immunol. 1991;147(11):3815-22.

17. Couper KN, Blount DG, Riley EM. IL-10: the master regulator of immunity to infection. J Immunol. 2008;180(9):5771-7.

18. Faist E, Mewes A, Baker C, Strasser T, Alkan S, Rieber P, et al. Prostaglandin E2 (PGE2)-dependent suppression of interleukin alpha (IL-2) production in patients with major trauma. J Trauma. 1987;27(8):837-48.

19. Sang N, Zhang J, Marcheselli V, Bazan NG, Chen C. Postsynaptically synthesized prostaglandin E2 (PGE2) modulates hippocampal synaptic transmission via a presynaptic PGE2 EP2 receptor. J Neurosci. 2005;25(43):9858-70.

20. Nussler AK, Billiar TR. Inflammation, immunoregulation, and inducible nitric oxide synthase. J Leukoc Biol. 1993;54(2):171-8.

21. Bogdan C. Nitric oxide and the immune response. Nat Immunol. 2001;2(10):907-16.

22. Nozaki Y, Fujita K, Wada K, Yoneda M, Kessoku T, Shinohara Y, et al. Deficiency of iNOS-derived NO accelerates lipid accumulation-independent liver fibrosis in non-alcoholic steatohepatitis mouse model. BMC Gastroenterol. 2015;15(1):42.

23. Li D, Liu QY, Sun W, Chen XP, Wang Y, Sun YX, et al. 1,3,6,7-Tetrahydroxy8-prenylxanthone ameliorates inflammatory responses resulting from the paracrine interactoin of adipocyts and macrophages. Br J Pharmacol. 2018;175:1590-606.

24. Gordon S. Alternative activation of macrophages. Nat Rev Immunol. 2003;3(1):23-35.

25. Zhang T, Fang ZJ, Linghu KG, Liu JX, Gan LS. Small molecule-driven SIRT3-autophagy-mediated NLRP3 inflammasome inhibition ameliorates inflammatory crosstalk between macrophages and adipocytes. $\mathrm{Br}$ J Pharmacol. 2020;177:4645-65.

26. Li D, Liu QY, Lu XQ, Li ZQ, Wang CM, Leung CH, et al. a-Mangostin remodels visceral adipose tissue inflammation to ameliorate agerelated metabolic disorders in mice. Aging. 2019;11(23):11084-103.

27. Davies LC, Jenkins SJ, Allen JE, Taylor PR. Tissue-resident macrophages. Nat Immunol. 2013;14(10):986.

28. Zheng XQ, Li K, Wei YD, Tie HT, Yi XY, Huang W. Nonsteroidal antiinflammatory drugs versus corticosteroid for treatment of shoulder pain: a systematic review and meta-analysis. Arch Phys Med Rehabil. 2014;95(10):1824-31.

29. Wolfensberger T, Herbort C. Treatment of cystoid macular edema with non-steroidal anti-inflammatory drugs and corticosteroids. In Macular Edema, Springer:2000;pp177-82.

30. Rodríguez LAG, Hernández-Díaz $\mathrm{S}$. The risk of upper gastrointestinal complications associated with nonsteroidal anti-inflammatory drugs, glucocorticoids, acetaminophen, and combinations of these agents. Arthrit Res Ther. 2001;3(2):98.

31. Azab A, Nassar A, Azab AN. Anti-inflammatory activity of natural products. Molecules. 2016;21(10):1321.

32. Aswad M, Rayan M, Abu-Lafi S, Falah M, Raiyn J, Abdallah Z, et al. Nature is the best sourse of anti-inflammatory drugs: indexing natural products for their anti-inflammatory bioactivity. Inflamm Res. 2018;67:67-75.

33. Li R, Morris-Natschke SL, Lee KH. Clerodane diterpenes: sources, structures, and biological activities. Nat Prod Rep. 2016;33(10):1166-226.

34. Siebert DJ. Salvia divinorum and salvinorin A: new pharmacologic findings. J Ethnopharmacol. 1994;43(1):53-6.

35. Maqueda AE, Valle M, Addy PH, Antonijoan RM, Puntes M, Coimbra J, et al. Naltrexone but not ketanserin antagonizes the subjective, cardiovascular, and neuroendocrine effects of salvinorin-A in humans. Int J Neuropsychopharmacol. 2016;19(7):pyw016.

36. Addy PH. Acute and post-acute behavioral and psychological effects of salvinorin A in humans. Psychopharmacology. 2012;220(1):195-204.

37. Mendelson JE, Coyle JR, Lopez JC, Baggott MJ, Flower K, Everhart ET, et al. Lack of effect of sublingual salvinorin A, a naturally occurring kappa opioid, in humans: a placebo-controlled trial. Psychopharmacology. 2011;214(4):933-9.

38. MacLean KA, Johnson MW, Reissig CJ, Prisinzano TE, Griffiths RR. Doserelated effects of salvinorin $A$ in humans: dissociative, hallucinogenic, and memory effects. Psychopharmacology. 2013;226(2):381-92.

39. Ranganathan M, Schnakenberg A, Skosnik PD, Cohen BM, Pittman B, Sewell RA, et al. Dose-related behavioral, subjective, endocrine, and 
psychophysiological effects of the $\mathrm{k}$ opioid agonist Salvinorin A in humans. Biol Psychiatry. 2012;72(10):871-9.

40. Johnson MW, MacLean KA, Reissig CJ, Prisinzano TE, Griffiths RR. Human psychopharmacology and dose-effects of salvinorin A, a kappa opioid agonist hallucinogen present in the plant Salvia divinorum. Drug Alcohol Depend. 2011;115(1-2):150-5.

41. Lynn WA, Golenbock DT. Lipopolysaccharide antagonists. Immunol Today. 1992;13(7):271-6

42. Raetz CR, Whitfield C. Lipopolysaccharide endotoxins. Annu Rev Biochem. 2002;71(1):635-700

43. Wang $P$, Liu F, Yang X, Liang Y, Li S, Su G, et al. Clerodane diterpenoids from Scutellaria formosana with inhibitory effects on NO production and interactions with iNOS protein. Phytochemistry. 2017;144:141-50.

44. Lee SR, Kim MS, Kim S, Hwang KW, Park SY. Constituents from Scutellaria barbata inhibiting nitric oxide production in LPSstimulated microglial cells. Chem Biodivers. 2017;14(11):e1700231.

45. Sun Z, Li Y, Jin DQ, Guo P, Xu J, Guo Y, et al. Structure elucidation and inhibitory effects on NO production of clerodane diterpenes from Ajuga decumbens. Planta Med. 2012;78(14):1579-93.

46. Sun Z, Li Y, Jin DQ, Guo P, Song H, Xu J, et al. neo-Clerodane diterpenes from Ajuga decumbens and their inhibitory activities on LPS-induced NO production. Fitoterapia. 2012;83(8):1409-14.

47. Dong B, Yang X, Liu W, An L, Zhang X, Tuerhong M, et al. Anti-inflammatory neo-clerodane diterpenoids from Ajuga pantantha. J Nat Prod. 2020;83(4):894-904

48. Fang ZJ, Zhang T, Chen SX, Wang YL, Zhou CX, Mo JX, et al. Cycloartane triterpenoids from Actaea vaginata with anti-inflammatory effects in LPS-stimulated RAW264.7 macrophages. Phytochemistry. 2019;160:1-10.

49. Liu QY, Li D, Wang AQ, Dong Z, Yin S, Zhang QW, et al. Nitric oxide inhibitory xanthones from the pericarps of Garcinia mangostana. Phytochemistry. 2016;131:115-23.

50. Wang Y, Lin J, Wang Q, Shang K, Pu DB, Zhang RH, et al. Clerodane diterpenoids with potential anti-inflammatory activity from the leaves and twigs of Callicarpa cathayana. Chin J Nat Med. 2019;17(12):953-62.

51. Li F, Zhang DB, Li JT, He FJ, Zhu HL, Li N, et al. Bioactive terpenoids from Croton laui. Nat Prod Res. 2019. https://doi.org/10.1080/14786 419.2019.1675062.

52. Lv HW, Luo JG, Meng DZ, Shan SM, Kong LY. Teucvisins A-E, five new neo-clerodane diterpenes from Teucrium viscidum. Chem Pharm Bull. 2014;62(5):472-6.

53. Yeon ET, Lee JW, Lee C, Jin Q, Jang H, Lee $\mathrm{D}$, et al. neo-Clerodane diterpenoids from Scutellaria barbata and their inhibitory effects on LPS-induced nitric oxide production. J Nat Prod. 2015;78(9):2292-6.

54. Somteds A, Tantapakul C, Kanokmedhakul K, Laphookhieo S, Phukhatmuen P, Kanokmedhakul S. Inhibition of nitric oxide production by clerodane diterpenoids from leaves and stems of Croton poomae Esser. Nat Prod Res. 2019. https://doi.org/10.1080/14786419.2019.1667350.

55. Lv H, Lu J, Kong LY. A new neo-clerodane diterpene from Ajuga decumbens. Nat Prod Res. 2014;28(3):196-200.

56. Lv HW, Luo JG, Zhu MD, Zhao HJ, Kong LY. neo-Clerodane diterpenoids from the aerial parts of Teucrium fruticans cultivated in China. Phytochemistry. 2015;119:26-31.

57. Wu TH, Cheng YY, Chen CJ, Ng LT, Chou LC, Huang LJ, et al. Three new clerodane diterpenes from Polyalthia longifolia var pendula. Molecules. 2014;19(2):2049-60

58. Zhang PZ, Zhang YM, Lin Y, Wang F, Zhang GL. Three new diterpenes from Dysoxylum lukii and their NO production inhibitory activity. J Asian Nat Prod Res. 2020;22(6):531-6.

59. Li Y, Zhu R, Zhang J, Wu X, Shen T, Zhou J, et al. Clerodane diterpenoids from the Chinese liverwort Jamesoniella autumnalis and their antiinflammatory activity. Phytochemistry. 2018;154:85-93.

60. Sadik CD, Kim ND, Luster AD. Neutrophils cascading their way to inflammation. Trends Immunol. 2011:32(10):452-60.

61. Giuliani S, Santicioli P, Tramontana M, Geppetti P, Maggi CA. Peptide $\mathrm{N}$-formyl-methionyl-leucyl-phenylalanine (FMLP) activates capsaicinsensitive primary afferent nerves in guinea-pig atria and urinary bladder. Br J Pharmacol. 1991;102(3):730.

62. Klebanoff SJ. In antimicrobial mechanisms in neutrophilic polymorphonuclear leukocytes. Semin Hematol. 1975;pp117-42.
63. Jaillon S, Galdiero MR, Del Prete D, Cassatella MA, Garlanda C, Mantovani A. In Neutrophils in innate and adaptive immunity. Semin Immunopathol. 2013; Springer: pp377-94

64. Chang FR, Hwang TL, Yang YL, Li CE, Wu CC, Issa HH, et al. Anti-inflammatory and cytotoxic diterpenes from Polyalthia longifolia var. pendula. Planta Med. 2006;72(14):1344-7.

65. Lee CL, Yen MH, Hwang TL, Yang JC, Peng CY, Chen CJ, et al. Anti-inflammatory and cytotoxic components from Dichrocephala integrifolia. Phytochemistry Lett. 2015;12:237-42.

66. Chang HL, Chang FR, Chen JS, Wang HP, Wu YH, Wang CC, et al. Inhibitory effects of 16-hydroxycleroda-3, 13 (14) E-dien-15-oic acid on superoxide anion and elastase release in human neutrophils through multiple mechanisms. Eur J Pharmacol. 2008:586(1-3):332-9.

67. Jang M, Pezzuto JM. Effects of resveratrol on 12-O-tetradecanoylphorbol-13-acetate-induced oxidative events and gene expression in mouse skin. Cancer Lett. 1998:134(1):81-9.

68. Khan AQ, Khan R, Qamar W, Lateef A, Rehman MU, Tahir M, et al. Geraniol attenuates 12-0-tetradecanoylphorbol-13-acetate (TPA)-induced oxidative stress and inflammation in mouse skin: possible role of p38 MAP Kinase and NF-KB. Exp Mol Pathol. 2013;94(3):419-29.

69. Rao TS, Currie JL, Shaffer AF, Isakson PC. Comparative evaluation of arachidonic acid (AA)-and tetradecanoylphorbol acetate (TPA)-induced dermal inflammation. Inflammation. 1993;17(6):723-41.

70. Simpson BS, Claudie DJ, Gerber JP, Pyke SM, Wang J, McKinnon RA, et al. In vivo activity of benzoyl ester clerodane diterpenoid derivatives from Dodonaea polyandra. J Nat Prod. 2011;74(4):650-7.

71. Salinas-Sánchez DO, Herrera-Ruiz M, Pérez S, Jiménez-Ferrer E, Zamilpa A. Anti-inflammatory activity of hautriwaic acid isolated from Dodonaea viscosa leaves. Molecules. 2012;17(4):4292-9.

72. Bautista E, Maldonado E, Ortega A. Neo-clerodane diterpenes from Salvia herbacea. J Nat Prod. 2012;75(5):951-8.

73. González-Chávez MM, Alonso-Castro AJ, Zapata-Morales JR, AranaArgáez V, Torres-Romero JC, Medina-Rivera YE, et al. Anti-inflammatory and antinociceptive effects of tilifodiolide, isolated from Salvia tiliifolia Vahl (Lamiaceae). Drug Dev Res. 2018;79(4):165-72.

74. Necas J, Bartosikova L. Carrageenan: a review. Vet Med. 2013;58(4):187-205.

75. Morris CJ. Carrageenan-induced paw edema in the rat and mouse. In Inflammation protocols. Springer: 2003;pp115-21.

76. Pierri EG, Castro RC, Vizioli EO, Ferreira CM, Cavalheiro AJ, Tininis AG, et al. Anti-inflammatory action of ethanolic extract and clerodane diterpenes from Casearia sylvestris. Rev Bras Farmacogn. 2017:27(4):495-501.

77. Carvalho JCT, Silva MFC, Maciel MAM, da Cunha Pinto A, Nunes DS, Lima RM, et al. Investigation of anti-inflammatory and antinociceptive activities of trans-dehydrocrotonin, a 19-nor-clerodane diterpene from Croton cajucara. Part 1. Planta Med. 1996;62(5):402-4.

78. ur Rehman T, Khan AU, Abbas A, Hussain J, Khan FU, Stieglitz K, et al. Investigation of nepetolide as a novel lead compound: Antioxidant, antimicrobial, cytotoxic, anticancer, anti-inflammatory, analgesic activities and molecular docking evaluation. Saudi Pharm J. 2018;26(3):422-9.

79. Rossi A, Pace S, Tedesco F, Pagano E, Guerra G, Troisi F, et al. The hallucinogenic diterpene salvinorin A inhibits leukotriene synthesis in experimental models of inflammation. Pharmacol Res. 2016;106:64-71.

80. Perazzo FF, Carvalho JCT, Rodrigues M, Morais EKL, Maciel MAM. Comparative anti-inflammatory and antinociceptive effects of terpenoids and an aqueous extract obtained from Croton cajucara Benth. Rev Bras Farmacogn. 2007;17(4):521-8.

81. Simpson BS, Luo X, Costabile M, Caughey GE, Wang J, Claudie DJ, et al. Polyandric acid A, a clerodane diterpenoid from the Australian medicinal plant Dodonaea polyandra, attenuates pro-inflammatory cytokine secretion in vitro and in vivo. J Nat Prod. 2014;77(1):85-91.

82. Haenszel W, Kurihara M, Segi M, Lee RK. Stomach cancer among Japanese in Hawaii. J Natl Cancer Inst. 1972;49(4):969-88.

83. Antonisamy $\mathrm{P}$, Dhanasekaran M, Ignacimuthu S, Duraipandiyan V, Balthazar JD, Agastian P, et al. Gastroprotective effect of epoxy clerodane diterpene isolated from Tinospora cordifolia Miers (Guduchi) on indomethacin-induced gastric ulcer in rats. Phytomedicine. 2014:21(7):966-9.

84. Monsen U, Broström O, Nordenvall B, Sörstad J, Hellers G. Prevalence of inflammatory bowel disease among relatives of patients with ulcerative colitis. Scand J Gastroenterol. 1987;22(2):214-8. 
85. Zheng JH, Lin SR, Tseng FJ, Tsai MJ, Lue SI, Chia YC, et al. Clerodane diterpene ameliorates inflammatory bowel disease and potentiates cell apoptosis of colorectal cancer. Biomolecules. 2019;9(12):762.

86. Babu NP, Pandikumar P, Ignacimuthu S. Anti-inflammatory activity of Albizia lebbeck Benth., an ethnomedicinal plant, in acute and chronic animal models of inflammation. J Ethnopharmacol. 2009;125(2):356-60.

87. Maintz L, Novak N. Histamine and histamine intolerance. Am J Clin Nutr. 2007;85(5):1185-96

88. Amann R, Schuligoi R, Lanz I, Donnerer J. Histamine-induced edema in the rat paw - effect of capsaicin denervation and a CGRP receptor antagonist. Eur J Pharmacol. 1995;279(2-3):227-31.

89. Butterfield JH. Increased leukotriene E4 excretion in systemic mastocytosis. Prostag Oth Lipid M. 2010;92(1-4):73-6.

90. Shinomiya H, Nakano M. Calcium ionophore A23187 does not stimulate lipopolysaccharide nonresponsive $\mathrm{C} 3 \mathrm{H} / \mathrm{HeJ}$ peritoneal macrophages to produce interleukin 1. J Immunol. 1987;139(8):2730-6.

91. Zhang DB, Tang ZS, Xie P, Liang YN, Yu JG, Zhang Z, et al. A pair of new neo-clerodane diterpenoid epimers from the roots of Croton crassifolius and their anti-inflammatory. Nat Pro Res. 2019. https://doi. org/10.1080/14786419.2019.1601193.

92. Ichihara Y, Takeya K, Hitotsuyanagi Y, Morita H, Okuyama S, Suganuma $\mathrm{M}$, et al. Cajucarinolide and isocajucarinolide: anti-inflammatory diterpenes from Croton cajucara. Planta Med. 1992;58(6):549-51.

93. Daina A, Michielin O, Zoete V. SwissADME: a free web tool to evaluate pharmacokinetics, drug-likeness and medicinal chemistry friendliness of small molecules. Sci Rep. 2017;7:42717.

94. Stinchcomb DM, Pranata J. Conformational and tautomeric equilibria of formohydroxamic acid in the gas phase and in aqueous solution. J Mol Struct. 1996;370(1):25-32.

95. Schröder A, Klein K, Winter S, Schwab M, Bonin M, Zell A, et al. Genomics of ADME gene expression: mapping expression quantitative trait loci relevant for absorption, distribution, metabolism and excretion of drugs in human liver. Pharmacogenomics J. 2013;13(1):12-20.

96. Hughes LD, Palmer DS, Nigsch F, Mitchell JB. Why are some properties more difficult to predict than others? A study of QSPR models of solubility, melting point, and Log P. J Chem Inf Model. 2008;48(1):220-32.

97. Ebeling $\mathrm{H}$, Edge A, Böhringer $\mathrm{H}$, Allen S, Crawford C, Fabian A, et al. The ROSAT Brightest Cluster Sample-I. The compilation of the sample and the cluster $\log \mathrm{N}-\log \mathrm{S}$ distribution. Mon Not R Astron Soc. 1998:301(4):881-914.

98. McCracken KG, Barger CP, Sorenson MD. Phylogenetic and structural analysis of the $\mathrm{HbA}(\mathrm{aA} / \beta \mathrm{A})$ and $\mathrm{HbD}(\mathrm{aD} / \beta \mathrm{A})$ hemoglobin genes in two high-altitude waterfowl from the Himalayas and the Andes: bar-headed goose (Anser indicus) and Andean goose (Chloephaga melanoptera). Mol Phylogen Evol. 2010;56(2):649-58.

99. Bade R, Chan HF, Reynisson J. Characteristics of known drug space. Natural products, their derivatives and synthetic drugs. Eur J Med Chem. 2010;45(12):5646-52.

100. Feng ZL, Lu XQ, Gan LS, Zhang QW, Lin LG. Xanthones, a promising antiinflammatory scaffold: structure, activity, and drug likeness analysis. Molecules. 2020;25(3):598

101. Camp D, Garavelas A, Campitelli M. Analysis of physicochemical properties for drugs of natural origin. J Nat Prod. 2015;78(6):1370-82.

102. Meade EA, Smith WL, Dewitt DL. Differential inhibition of prostaglandin endoperoxide synthase (cyclooxygenase) isozymes by aspirin and other non-steroidal anti-inflammatory drugs. J Biol Chem. 1993;268(9):6610-4.

103. Ertl P, Rohde B, Selzer P. Fast calculation of molecular polar surface area as a sum of fragment-based contributions and its application to the prediction of drug transport properties. Eur J Med Chem. 2000;43(20):3714-7
104. Prasanna S, Doerksen R. Topological polar surface area: a useful descriptor in 2D-QSAR. Curr Med Chem. 2009;16(1):21-41.

105. Kamlet MJ, Doherty RM, Abraham MH, Marcus Y, Taft RW. Linear solvation energy relationship: an improved equation for correlation and prediction of octanol/water partition coefficients of organic nonelectrolytes (including strong hydrogen bond donor solutes). J Phys Chem A. 1988;92(18):5244-55

106. Tarko L. Using the bond order calculated by quantum mechanics to identify the rotatable bonds. Rev Chim. 2011:62:135-8.

107. Veber DF, Johnson SR, Cheng HY, Smith BR, Ward KW, Kopple KD. Molecular properties that influence the oral bioavailability of drug candidates. Eur J Med Chem. 2002;45(12):2615-23.

108. Meanwell NA. Improving drug candidates by design: a focus on physicochemical properties as a means of improving compound disposition and safety. Chem Res Toxicol. 2011;24(9):1420-56.

109. Daina A, Michielin O, Zoete V. iLOGP: a simple, robust, and efficient description of n-octanol/water partition coefficient for drug design using the GB/SA approach. J Chem Inf Model. 2014;54(12):3284-301.

110. Box K, Comer J. Using measured pKa, LogP and solubility to investigate supersaturation and predict BCS class. Curr Drug Metab. 2008;9(9):869-78.

111. Golumbic C, Orchin M. Partition studies. V. Partition coefficients and ionization constants of methyl-substituted pyridines and quinolines. J Am Chem Soc. 1950;72(9):4145-7.

112. Jorgensen WL, Duffy EM. Prediction of drug solubility from structure. Adv Drug Del Rev. 2002;54(3):355-66.

113. Di L, Kerns EH. Solution stability-plasma, gastrointestinal, bioassay. Curr Drug Metab. 2008;9(9):860-8.

114. Daina A, Zoete V. A boiledegg to predict gastrointestinal absorption and brain penetration of small molecules. ChemMedChem. 2016:11(11):1117-21.

115. Bode H, Brendel E, Ahr G, Fuhr U, Harder S, Staib A. Investigation of nifedipine absorption in different regions of the human gastrointestinal (GI) tract after simultaneous administration of 13C-and 12C-nifedipine. Eur J Clin Pharmacol. 1996;50(3):195-201.

116. Wilhelm I, Krizbai IA. In vitro models of the blood-brain barrier for the study of drug delivery to the brain. Mol Pharm. 2014;11(7):1949-63.

117. Boulton DW, DeVane CL, Liston HL, Markowitz JS. In vitro P-glycoprotein affinity for atypical and conventional antipsychotics. Life Sci. 2002;71(2):163-9.

118. Brewer CT, Chen T. Hepatotoxicity of herbal supplements mediated by modulation of cytochrome P450. Int J Mol Sci. 2017;18(11):2353.

\section{Publisher's Note}

Springer Nature remains neutral with regard to jurisdictional claims in published maps and institutional affiliations. 